\section{La baja visión. La psicología aplicada a la oftalmología}

\section{Low vision. Phsychology applied for ophthalmology}

En los años que llevo ejerciendo la oftalmología me he encontrado con la terrible situación de explicar el tremendo pronóstico de algunas patologías y las escasas posibilidades de éxito con la terapia.

Los antiangiogénicos, TNF, terapias fotodinámicas, láseres, etc, han mejorado ese terrible pronóstico. El advenimiento de las células madre es para, pacientes y oftalmólogos, la gran esperanza, pero hasta entonces ... el paciente sigue saliendo de la consulta triste y deprimido.

La ayuda de baja visión, facilita al paciente «defenderse» por la vida y alivia la desesperación del drama de la ceguera.

A pesar de las técnicas actuales, es la ayuda psicológica, la que contribuye, no a ver, pero sí a «graduar» la esperanza.

Las ayudas visuales que utilizamos más frecuentemente son:

Filtros. Mejoran la sensibilidad espectral evitando deslumbramientos.

Telescopios. Aumentar el tamaño de la imagen retiniana.

Telemicroscopios. Sistemas de lentes, acoplados en gafas, aumentan el tamaño de la imagen.

Gafas prismáticas. Sistema binocular para visión próxima con fuertes adiciones. Incorporan prisma base nasal (convergencia).

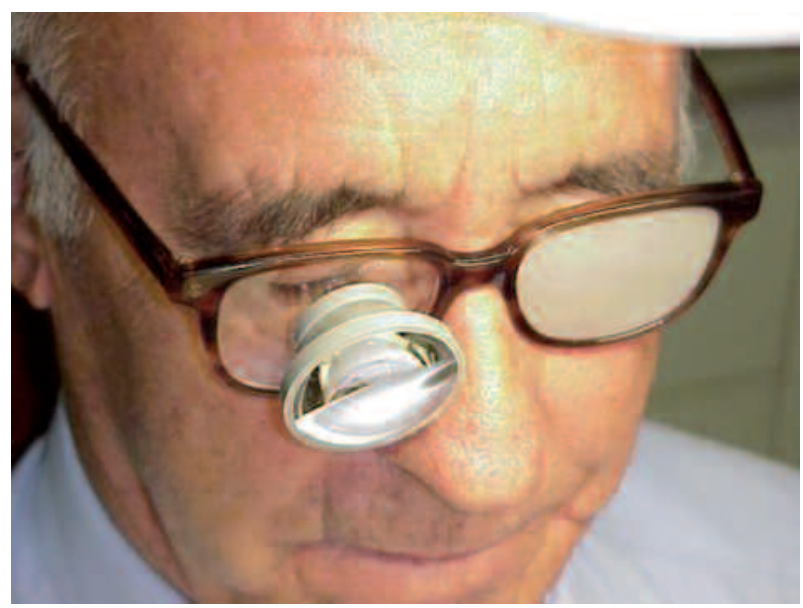

Fig. 1: Microscopio monocular acoplado en gafa.
Lupas de campo claro. Apoyo para la lectura. Gran luminosidad.

Ayudas electrónicas. Sistemas de gran aumento basados en la electrónica.

Flexos especiales. Mejoran el contraste, disminuyendo el esfuerzo.

Las patologías más frecuentes son: DMAE, retinopatía diabética, glaucomas avanzados, traumatismos oculares, distrofias retinianas, problemas circulatorios, de la vía óptica, corneales y cataratas.

Casos como los descritos a continuación aclaran que existen situaciones en las que la forma de proceder marca la diferencia entre conseguir algo positivo o no.

Caso 1. Paciente de 74 años, operado hace 4 años de catarata binocular con problemas en la visión central. Fue diagnosticado de DMAE y tratado con terapia fotodinámica. AV OD: PPL y OI: 0,2.

Anamnesis se aprecia un elevado interés por ver la TV y pasear. No lee.

Argumenta problemas con la luz, prescribimos filtros de corte CPF 527 para la calle, obteniéndose un mayor contraste.

Para ver la TV, prescribimos: Telescopio Galileo de $2 \mathrm{X}$ para OI, montado en gafa.

Caso 2. Paciente de 27 años diagnosticado de síndrome de Stargardt.

AV OD: 0,2 y OI: 0,15 .

Anamnesis observamos elevada aceptación a cualquier tipo de ayuda. Fuerte fotofobia. Estudia y trabaja.

Probamos Telescopio, con malos resultados por problemas de binocularidad. Montamos en OD un

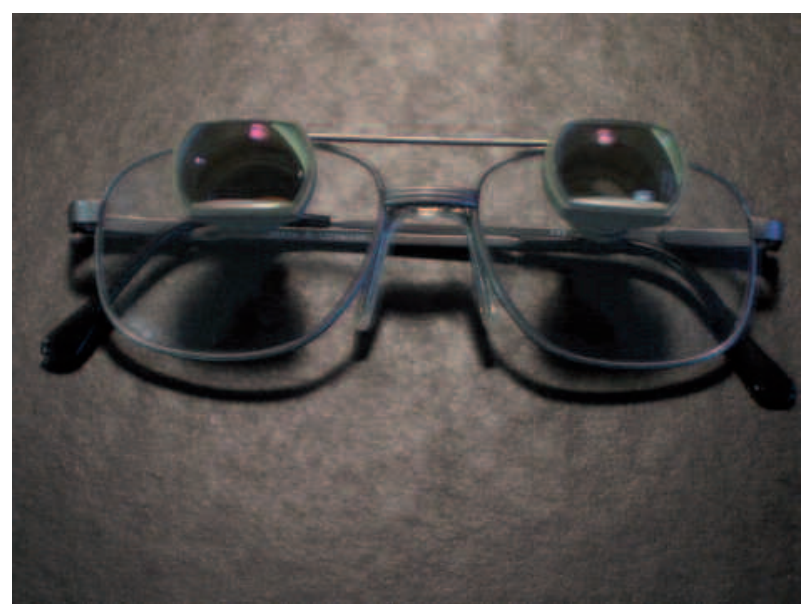

Fig. 2: Telescopios de Galileo en montaje binocular superior, que permite montar refracción paciente. 
Telescopio de 2X, y acoplamos una lente de aproximación de $+6,25$, con buenos resultados.

El factor psicológico, la atención al paciente, la paciencia, sentirse escuchado, derivan, en un aumento de confianza del paciente y mayor predisposición para aceptar ayudas.

Existen dos grandes barreras en el paciente de Baja Visión:

- La edad. Es primordial que encuentre un estímulo importante, para seguir luchando por su visión.

- Asimilación de su problemática. Un paciente con una patología establecida es más receptivo y conocedor de sus limitaciones. No busca ver bien, sino encontrar alguna ayuda El paciente que ha perdido la visión recientemente no tiene asimilado que no volverá a ver como veía. Acude con la esperanza de una solución que le permita ver bien. Esto en patologías de Baja Visión son metas prácticamente inalcanzables.

En definitiva, la Baja Visión no mejora la AV, pero trata de sacar su mejor rendimiento. Es la psicología aplicada a la oftalmología.

Torres-Urbano $\mathrm{T}^{1}$, Belmar-Aparicio $\mathrm{F}^{2}$, Roda-Marzal V ${ }^{2}$, Roda-Cámara $\mathrm{V}^{2}$

${ }^{1}$ Centro de especialidades Juan Llorens y Torrente. Hospital General y Universitario. Valencia.

2 Optometrista. Contact Visión. Valencia. E-mail: tioma@comv.es 